\title{
EXPECTED DIRECT SEISMIC LOSSES ASSESSMENT USING GIS. CASE STUDY FOR IAŞI MUNICIPALITY
}

\author{
Radu VĂCĂREANU - Professor, PhD, Technical University of Civil Engineering, Faculty of Buildings \\ e-mail: radu.vacareanu@utcb.ro \\ Dan LUNGU - Professor, PhD, Technical University of Civil Engineering, Faculty of Buildings \\ e-mail: lungud@utcb.ro
}

Alexandru ALDEA - Associate Professor, PhD, Technical University of Civil Engineering, Faculty of Buildings, e-mail: aldea@utcb.ro

Cristian ARION - Lecturer, PhD, Technical University of Civil Engineering, Faculty of Buildings

e-mail: arion@utcb.ro

Cristian NEAGU - Engineer, PhD student, Technical University of Civil Engineering, Faculty of Buildings, e-mail: cristi.neagu@utcb.ro

Florian GĂMAN - Associate Professor, PhD, Technical University of Civil Engineering, Faculty of Buildings, email: gflorin@utcb.ro

Florian PETRESCU - Associate Professor, PhD, Technical University of Civil Engineering, Faculty of Buildings, e-mail: florianp@utcb.ro

Mihaela ALDEA - Assistant Professor, PhD, Technical University of Civil Engineering, Faculty of Buildings, email: imihaela@utcb.ro

\begin{abstract}
Expected direct seismic losses assessment is performed on probabilistic basis using world-wide accepted methodologies for two study areas located in Iasi Municipality. The probabilistic assessment refers to the following issues: site-dependent seismic hazard, expected seismic response of buildings, seismic fragility of structures, expected seismic damage. The analysis of the spatial distribution of the existing building stock as well as the presentation of the results on expected direct seismic losses are performed using geographic information systems (GIS)
\end{abstract}

Keywords: hazard, fragility, risk, losses, seismic

\section{Introduction}

This paper presents an evaluation model for the expected direct seismic losses applied on two study areas in the Iasi Municipality. The elements presented are a synthesis of the results obtained within CERSIS research project financed by the National Authority for Scientific Research between 2007 and 2010. The expected seismic losses were assessed in the following steps:

- probabilistic assessment of seismic hazard on selected sites in Iasi Municipality;

- evaluation of expected seismic capacity and response for building typologies representative for Iasi Municipality;

- development of a functional model for seismic fragility/vulnerability analysis for building typologies representative for Iasi Municipality;

- development of a functional model for seismic risk analysis; evaluation of the expected damage degree and of the expected direct seismic losses for buildings and lifelines within two study areas in Iasi Municipality.

\section{Probabilistic Assessment of Seismic Hazard in Iasi Municipality}

The mean seismic hazard curve from Vrancea subcrustal source for Iasi Municipality obtained within CERSIS Project is presented in Figure 1. Details on the probabilistic seismic hazard assessment in Iasi Municipality can be found in [3]. 


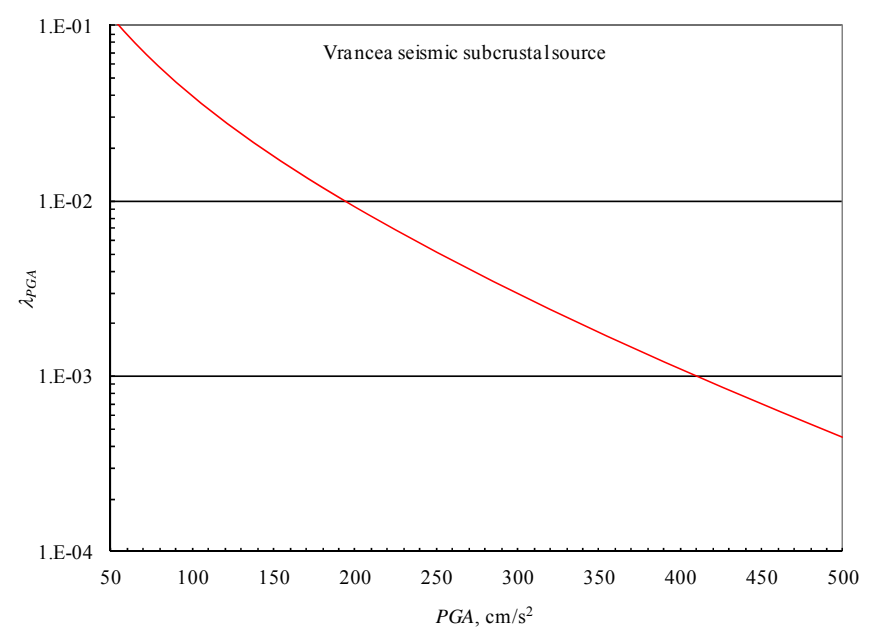

Fig. 1 - Mean seismic hazard curve for Iasi Municipality

The correspondence between the values of the peak ground acceleration, PGA and the mean recurrence intervals, MRI is reported in Table 1.

Table 1

Peak ground horizontal acceleration values with different mean recurrence intervals for Iasi Municipality

\begin{tabular}{|c|c|c|c|c|c|}
\hline$M R I$, years & 30 & 100 & 225 & 475 & 975 \\
\hline$P G A, \mathrm{~cm} / \mathrm{s}^{2}$ & 100 & 190 & 250 & 320 & 400 \\
\hline
\end{tabular}

Peak ground horizontal acceleration values with different mean recurrence intervals for Iasi from Table 1, $P G A_{M R I}$, are considered multiplication factors for normalized spectral ordinates, $\beta(T)$, from P100-1/2006 design code. In this way the elastic response spectra for absolute accelerations with different mean recurrence intervals, $S A_{M R I}(T)$, are obtained:

$$
S A_{M R I}(T)=P G A_{M R I} \cdot \beta(T)
$$

For the validation of the results, in Figure 2 the (i) elastic response spectra is presented for absolute accelerations obtained by averaging individual spectra corresponding to 15 strong ground motions recorded in Moldova area in August 30 1986, May 30 and 311990 Vrancea subcrustal earthquakes. Moreover, the elastic response spectra for absolute accelerations with 30 and 100 years mean recurrence interval obtained with relation (1) are also presented in the same figure.

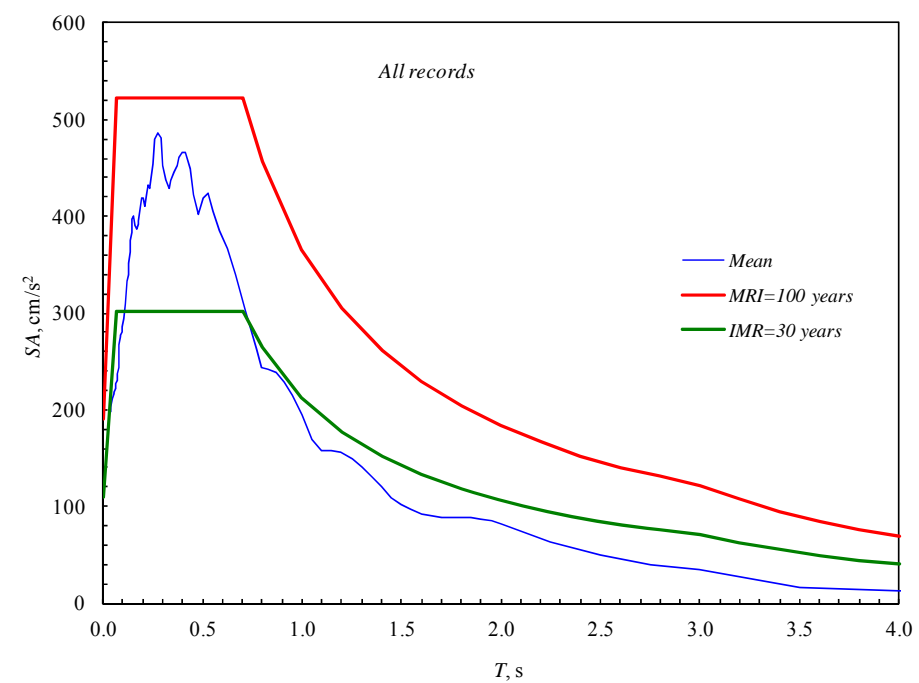

Fig. 2 - Mean elastic response spectrum of absolute accelerations for 15 ground motions recorded in Moldova area and elastic response spectra of absolute accelerations with 30 and 100 years mean recurrence interval 


\section{Expected Seismic Capacity Evaluation and Seismic Response for Building Typologies Representative for Iasi Municipality}

The CERSIS project utilised building typologies defined in the RISK-UE European Project (2001-2004, $5^{\text {th }}$ Framework), in Workpackage 1 - European distinctive features, inventory database and typology (UTCB in charge). Details on buildings typologies can be found in [2].

The capacity curves developed in the CERSIS project are based on the seismic design parameters according to different versions of P13 and P100 earthquake-resistant design codes and on the engineering judgement. The building capacity curve model is described by two control points, namely: (i) yielding capacity and (ii) ultimate capacity. The displacement and lateral force values corresponding to the two control points of capacity curves of buildings typologies are obtained from seismic design coefficient, fundamental period of vibration, modal participation factor and modal mass, ductility factor and building typology over-strength. Details about the capacity curves parameters are shown in [4]. As an example, in Table 2 are presented the spectral displacement values corresponding to yielding capacity, $D c$ and ultimate capacity, $D u$, the spectral acceleration values corresponding to yielding capacity, $A c$ and ultimate capacity, $\mathrm{Au}$, for low rise, $L$, medium rise, $M$ and high rise, $H$ reinforced concrete frame buildings, $C 1$ and shearwall buildings, $C 2$ designed for Iasi Municipality according to P13-70 code.

Table 2

Capacity curves parameters $-1970-1977$

\begin{tabular}{|c|c|c|c|c|}
\hline \multirow{2}{*}{$\begin{array}{c}\text { Building } \\
\text { type }\end{array}$} & \multicolumn{2}{|c|}{ Yielding capacity } & \multicolumn{2}{c|}{ Ultimate capacity } \\
\cline { 2 - 5 } & $D_{c}(\mathrm{~cm})$ & $A_{c}(' \mathrm{~g})$ & $D_{u}(\mathrm{~cm})$ & $A_{u}($ 'g) \\
\hline$C 1 L$ & 0.3 & 0.078 & 2.3 & 0.195 \\
\hline$C 1 M$ & 0.8 & 0.048 & 5.7 & 0.120 \\
\hline$C 1 H$ & 0.9 & 0.035 & 6.6 & 0.088 \\
\hline$C 2 L$ & 0.2 & 0.106 & 1.4 & 0.212 \\
\hline$C 2 M$ & 0.6 & 0.096 & 3.6 & 0.192 \\
\hline$C 2 H$ & 1.0 & 0.061 & 5.8 & 0.121 \\
\hline
\end{tabular}

The expected seismic response of representative building typologies from Iasi Municipality was obtained through capacity spectrum method [1] using as seismic demand the elastic response spectra for absolute accelerations determined with relation (1) for different mean recurrence intervals.

\section{Seismic Fragility Assessment for Representative Building Typologies in Iasi Municipality}

\subsection{Seismic Fragility Functions Based on Intensity}

The calibration of seismic fragility functions based on intensity is performed using building damage data occurred in Iasi during March 41977 Vrancea strong earthquake. The study presented in [5] on damage of buildings in Iasi was conducted on a sample that includes several thousand masonry and reinforced concrete buildings. The study results were expressed in damage grade, $D G$ and corresponding macro seismic intensity, $I$. DG was quantified according to the macro-seismic intensity scale MSK. The damage of the buildings is expressed as the mean and standard deviation of damage grade $D G$ for a given macro-seismic intensity and for a given building typology. The damage grades used in the post-earthquake survey are [5]: 1 - Negligible, 2 - Slight, 3 - Moderate, 4 - Heavy and 5 - Collapse.

The probability distribution of damage grade is calculated using the Beta probability density function:

$$
f_{X}(x)= \begin{cases}\frac{1}{B(q, r)} \cdot \frac{(x-a)^{q-1} \cdot(b-x)^{r-1}}{(b-a)^{q+r-1}}, & a \leq x \leq b \\ \rightarrow 0, & \text { otherwise }\end{cases}
$$


where $\mathrm{x}$ is damage grade, $\mathrm{a}=0, \mathrm{~b}=6$, and $\mathrm{B}(\mathrm{q}, \mathrm{r})$ is the Beta function:

$$
B(q, r)=\frac{\Gamma(q) \cdot \Gamma(r)}{\Gamma(q+r)}
$$

The parameters $q$ and $r$ of probability distribution are related to the mean and standard deviation of the random damage grade, DG as follows:

$$
\begin{aligned}
& \text { Mean } D G=a+\frac{q}{q+r}(b-a) \\
& (\text { St.dev.DG })^{2}=\frac{q \cdot r}{(q+r)^{2}(q+r+1)}(b-a)^{2}
\end{aligned}
$$

The beta cumulative distribution function of damage grade DG is obtained with the following relation:

$$
F_{X}(x)=\int_{a}^{x} f_{X}(u) d u
$$

In Figure 3 and 4 are presented examples of probability distributions of damage grade, DG for masonry buildings with reinforced concrete slabs, built after 1950 .

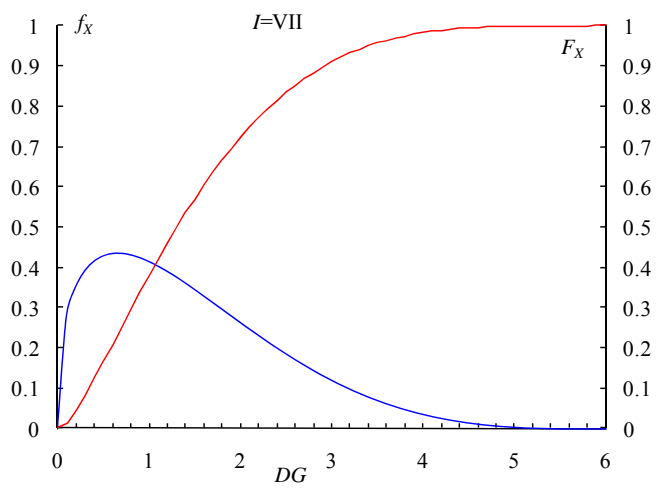

Fig. 3 - Seismic intensity VII - Damage grade probability distributions for masonry buildings with reinforced concrete slabs, built after 1950

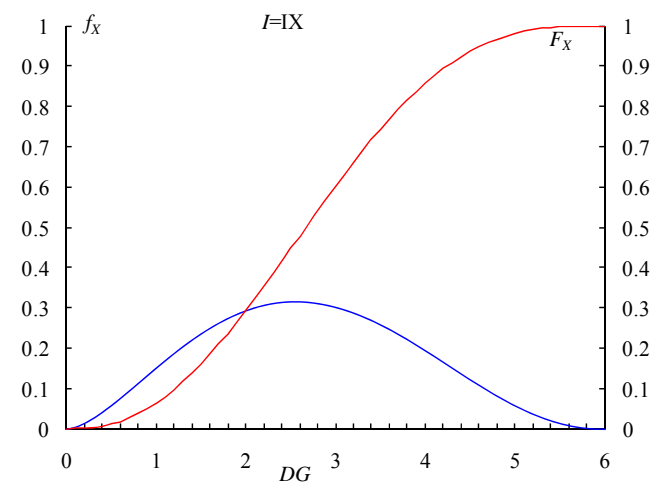

Fig. 4 - Seismic intensity IX - Damage grade probability distributions for masonry buildings with reinforced concrete slabs, built after 1950

The damage probability matrix (DPM) indicates in a discrete form the conditional probability of a damage grade / state $\mathrm{j}$, produced by a seismic intensity $\mathrm{i}, \mathrm{P}[\mathrm{DG}=\mathrm{j} \mid \mathrm{I}=\mathrm{i}]$. The damage probability matrix elements are obtained with the following relation:

$$
P(k)=F_{X}(k+1)-F_{X}(k)
$$

where $\mathrm{k}(\mathrm{k}=0,1,2,3,4,5)$ correspond to damage grade $\mathrm{DG}$.

Table 3 presents the damage probability matrix for masonry buildings with reinforced concrete slabs, built after 1950 .

Table 3

Damage probability matrix for masonry buildings with reinforced concrete slabs, built after 1950

\begin{tabular}{|c|c|c|c|c|c|c|c|}
\hline \multirow{2}{*}{$\begin{array}{c}\text { Damage } \\
\text { grade } \\
D G\end{array}$} & \multirow{2}{*}{$\begin{array}{c}\text { Damage } \\
\text { state }\end{array}$} & \multicolumn{7}{|c|}{ Seismic intensity } \\
\cline { 3 - 8 } & $\mathrm{VI}^{1 / 2}$ & VII & VII $^{1 / 2}$ & VIII & VIII $^{1 / 2}$ & IX \\
\hline 0 & Undamaged & $5.63 \mathrm{E}-01$ & $4.80 \mathrm{E}-01$ & $3.79 \mathrm{E}-01$ & $2.78 \mathrm{E}-01$ & $6.29 \mathrm{E}-02$ & $1.39 \mathrm{E}-02$ \\
\hline 1 & Negligible & $2.92 \mathrm{E}-01$ & $3.48 \mathrm{E}-01$ & $3.43 \mathrm{E}-01$ & $3.58 \mathrm{E}-01$ & $2.30 \mathrm{E}-01$ & $1.03 \mathrm{E}-01$ \\
\hline 2 & Slight & $1.11 \mathrm{E}-01$ & $1.35 \mathrm{E}-01$ & $1.88 \mathrm{E}-01$ & $2.35 \mathrm{E}-01$ & $3.09 \mathrm{E}-01$ & $2.34 \mathrm{E}-01$ \\
\hline 3 & Moderate & $3.01 \mathrm{E}-02$ & $3.29 \mathrm{E}-02$ & $7.28 \mathrm{E}-02$ & $1.03 \mathrm{E}-01$ & $2.55 \mathrm{E}-01$ & $3.11 \mathrm{E}-01$ \\
\hline 4 & Heavy & $4.41 \mathrm{E}-03$ & $3.76 \mathrm{E}-03$ & $1.63 \mathrm{E}-02$ & $2.52 \mathrm{E}-02$ & $1.24 \mathrm{E}-01$ & $2.57 \mathrm{E}-01$ \\
\hline 5 & Collapse & $1.41 \mathrm{E}-04$ & $7.41 \mathrm{E}-05$ & $9.48 \mathrm{E}-04$ & $1.60 \mathrm{E}-03$ & $1.91 \mathrm{E}-02$ & $8.09 \mathrm{E}-02$ \\
\hline
\end{tabular}




\subsection{Seismic Fragility Functions Based on Spectral Displacement}

The parameters of the seismic fragility functions based on spectral displacement were calibrated for reinforced concrete frames and shear-wall buildings (which represent the most of Iasi multistorey residential buildings) that are analysed in CERSIS project [1].

The fragility curves are developed for Slight, Moderate, Extensive and Complete damage states, as they are described in [1]. The probability of reaching or exceeding a certain damage grade is modelled through the lognormal distribution function. For structural damage, the probability of reaching or exceeding a certain damage state, ds, given the spectral displacement, $\mathrm{Sd}$, is obtained by the following relation:

$$
\mathrm{P}\left[d s \mid \mathrm{S}_{\mathrm{d}}\right]=\Phi\left[\frac{1}{\beta_{d s}} \ln \left(\frac{\mathrm{S}_{\mathrm{d}}}{\overline{\mathrm{S}}_{d, d s}}\right)\right]
$$

where:

$\overline{\mathrm{S}}_{\mathrm{d}, \mathrm{ds}}$ is the median spectral displacement value for which the building reaches the threshold of the damage state ds;

$\beta \mathrm{ds} \quad$ standard deviation of natural logarithm of spectral displacement for damage state ds;

$\Phi \quad$ is normal standard distribution function.

Table 4 shows the mean and the logarithm of standard deviation values of spectral displacement for Slight, Moderate, Extensive and Complete damage state for low rise, L, medium rise, $\mathrm{M}$ and high rise, $\mathrm{H}$ reinforced concrete frames, $\mathrm{C} 1$ and shear-walls, $\mathrm{C} 2$ buildings designed according to P13-70 earthquake-resistant design code in Iasi Municipality.

Table 4

Seismic fragility curve parameters (1970-1977)

\begin{tabular}{|c|c|c|c|c|c|c|c|c|c|c|}
\hline \multicolumn{10}{|c|}{ Building proprieties } & \multicolumn{10}{|c|}{ Spectral displacement, cm } \\
\hline \multirow{2}{*}{$\begin{array}{c}\text { Building } \\
\text { type }\end{array}$} & \multicolumn{2}{|c|}{ Height, $\mathrm{m}$} & \multicolumn{2}{c|}{ Slight } & \multicolumn{2}{c|}{ Moderate } & \multicolumn{2}{c|}{ Extensive } & \multicolumn{2}{c|}{ Complete } \\
\hline & Total & Modal & $\overline{\mathrm{S}}_{\mathrm{d}, \mathrm{U}}$ & $\beta_{\mathrm{U}}$ & $\overline{\mathrm{S}}_{\mathrm{d}, \mathrm{M}}$ & $\beta_{\mathrm{M}}$ & $\overline{\mathrm{S}}_{\mathrm{d}, \mathrm{E}}$ & $\beta_{\mathrm{E}}$ & $\overline{\mathrm{S}}_{\mathrm{d}, \mathrm{C}}$ & $\beta_{\mathrm{C}}$ \\
\hline$C 1 \mathrm{~L}$ & 5.70 & 3.99 & 2 & 0.95 & 3 & 0.90 & 6 & 0.85 & 14 & 0.95 \\
\hline$C 1 M$ & 17.10 & 11.97 & 4 & 0.70 & 6 & 0.75 & 12 & 0.85 & 28 & 1.00 \\
\hline$C 1 \mathrm{H}$ & 28.50 & 17.10 & 4 & 0.70 & 7 & 0.80 & 13 & 0.90 & 30 & 1.00 \\
\hline$C 2 \mathrm{~L}$ & 5.70 & 3.99 & 2 & 1.00 & 3 & 1.00 & 6 & 1.00 & 14 & 0.95 \\
\hline$C 2 \mathrm{M}$ & 17.10 & 11.97 & 3 & 0.80 & 6 & 0.80 & 12 & 0.80 & 28 & 1.00 \\
\hline$C 2 \mathrm{H}$ & 28.50 & 17.10 & 3 & 0.70 & 6 & 0.75 & 13 & 0.85 & 30 & 0.95 \\
\hline
\end{tabular}

\section{Assessment of Expected Damage Grade for Buildings from Two Study Areas in Iasi Municipality}

The expected direct structural losses for different damage state are defined as a percent of losses corresponding to complete damage state. According to [1], the relation between damage states and replacement costs is as follows:

$\begin{array}{ll}\text { Slight damages: } & 2 \% \text { of replacement value } \\ \text { Moderate damages: } & 10 \% \text { of replacement value } \\ \text { Heavy damages: } & 50 \% \text { of replacement value. }\end{array}$

The expected direct losses and mean damage grades are determined as weighted averages, the weights being the probabilities of different damage states. Expected damage state is determined based on mean damage grade, by the following algorithm:

- if mean damage grade $<0.5$, then the expected state is undamaged;

- $\quad$ if $0.5 \leq$ mean damage grade $<1.5$, then the expected state is slight; 
- if $1.5 \leq$ mean damage grade $<2,5$, then the expected state is moderate;

- if $2,5 \leq$ mean damage grade $<3,5$, then the expected state is extensive;

- if mean damage grade $\geq 3,5$, then the expected state is complete.

Expected direct seismic losses are evaluated for two study areas in Iasi Municipality, as follows:

- North - Copou study area - Codrescu - located in Copou neighbourhood with approximately $6 \mathrm{~km}^{2}$

- East - Podu Ros study area - Tudor Vladimirescu - located in Tudor Vladimirescu neighbourhood with approximately $9 \mathrm{~km}^{2}$.

Figures 5 and 6 present the territorial distribution of North area buildings by bulging typology, respectively by height level.

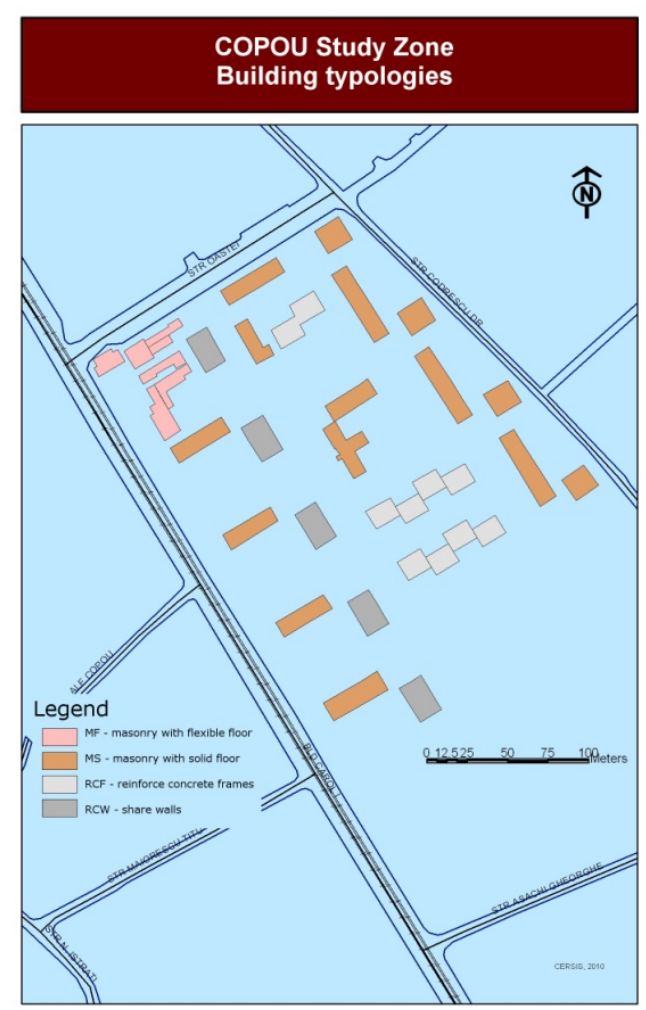

Fig. 5 - Building typology of North area buildings

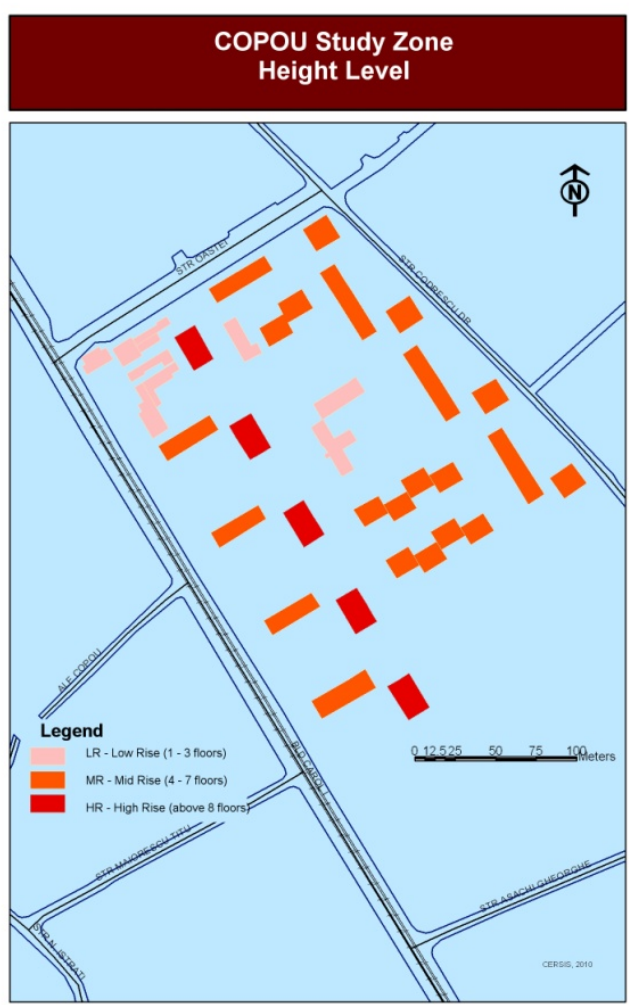

Fig. 6 - Height level of North area buildings

For the residential buildings in both study areas the following distribution of the expected damage states are obtained:

- for earthquake scenario with $M R I=100$ years

- 61 buildings are expected to be in slight damage state

- 13 buildings are expected to be in moderate damage state

- for earthquake scenario with $M R I=475$ years

- 5 buildings are expected to be in slight damage state

- 61 buildings are expected to be in moderate damage state

- 8 buildings are expected to be in heavy damage state

- for earthquake scenario with $M R I=975$ years

- 66 buildings are expected to be in moderate damage state

- 8 buildings are expected to be in heavy damage state. 
As an example, Figures 7 and 8 present the expected damage state, respectively the expected direct structural losses of North area buildings for MRI $=475$ years earthquake.

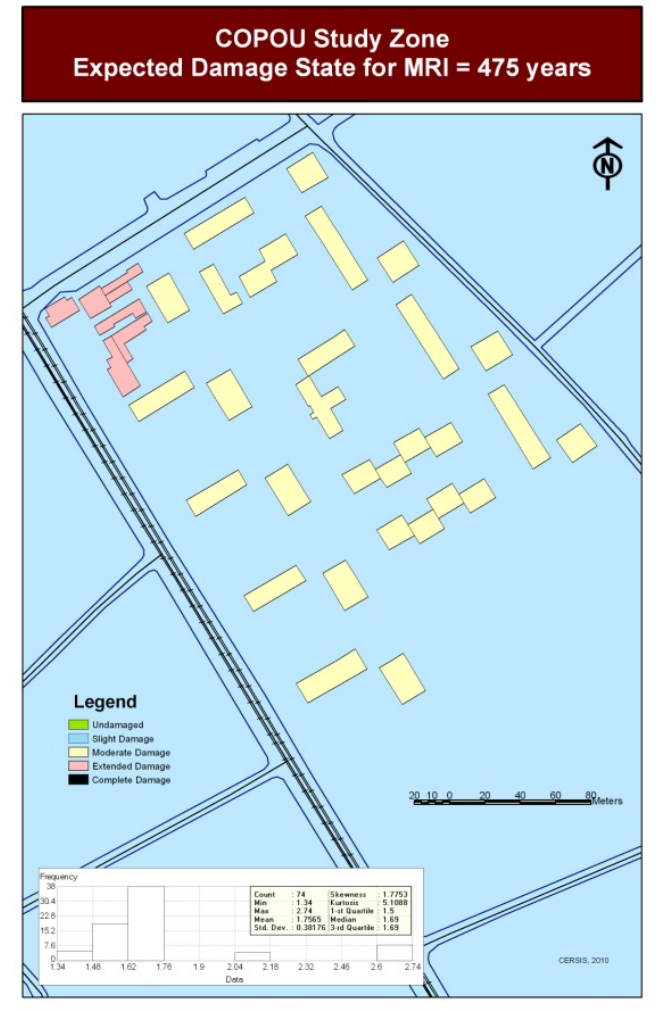

Fig. 7 - Expected damage state of North area buildings for $M R I=475$ years earthquake

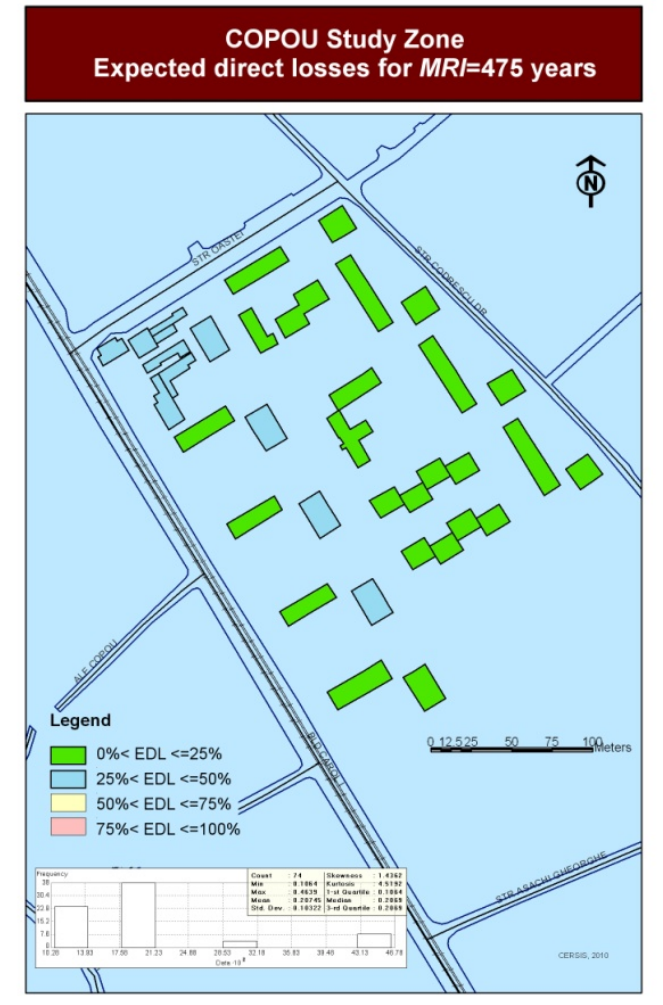

Fig. 8 - Expected direct structural losses of North area buildings for $M R I=475$ years earthquake

\section{Acknowledgments}

The paper is based on the results obtained in CERSIS Project, Contract no. 31-023/2007, financed within PNCDI II by National Agency for Scientific Research through National Centre for Programmes Management. The authors acknowledge the scientific contribution of CERSIS Project partners: National Centre for Seismic Risk Reduction, Technical University "Gheorghe Asachi” Iasi and Data Invest Iasi.

\section{References}

[1] HAZUS, Technical Manual (1997), Earthquake Loss Estimation Methodology, Vol. 3.

[2] Lungu, D., Aldea, A., Arion, C., Văcăreanu, R. (2005). WP1 - European Distinctive Features, Inventory Database and Typology, Bulletin of the Technical University of Civil Engineering Bucharest, 2/2003, p. 12-42

[3] Văcăreanu, R., Lungu, D., Aldea, A., Arion, C., (2009). Evaluarea probabilistica a hazardului seismic din sursa subcrustala Vrancea pentru municipiul Iasi. A 4-a Conferinta Nationala de Inginerie Seismica, December 2009, Editura Conspress, ISBN 978-973-100-096-1 (in Romanian)

[4] Văcăreanu, R., Lungu, D., Arion, C. (2009). Capacity curves and fragility functions for representative building types in Bucharest. A 4-a Conferinta Nationala de Inginerie Seismica, December 2009, Ed. Conspress, ISBN 978-973-100-096-1

[5] Working Group Vulnerability and Risk Analysis for individual structures and systems of EAEE, Report to $8^{\text {th }}$ ECEE (1986). Some data on vulnerability obtained in European countries. 